\title{
Rastros e percursos de uma pesquisa: sociedade civil e política educativa no Uruguai nos anos 1980-2010
}

\author{
Traces and paths of a research: civil society and educational policy in Uruguay \\ in $1980-2010$
}

Gabriela Rodríguez Bissio

Universidad de la República - Uruguay

\section{RESUMO:}

Este artigo é baseado em um projeto de pesquisa voltado para organizações da sociedade civil uruguaia que participam da implementação de políticas públicas de educação. $\mathrm{O}$ estudo analisou entrevistas com profissionais dessas organizações que trabalham em programas educacionais para os pobres na cidade de Montevidéu. Este texto aborda algumas das decisões metodológicas e organizacionais que orientaram a análise do material obtido no trabalho de campo e examina algumas das considerações levantadas em relação à análise microfísica dos projetos educacionais e à lógica governamental a eles associada.

Palavras-chave: Educação; Sociedade civil; Estado; Metodologia; Pesquisa.

\section{ABSTRACT:}

This article is based on a research project which focused on Uruguayan civil society organizations that take part in the implementation of public educational policies. The study analyzed interviews with professionals from those organizations working in educational programs for the poor in the city of Montevideo. This text tackles some of the methodological and organizational decisions that guided the analysis of the material obtained from field work and examines some of the considerations that arouse regarding a microphysical analysis of educational projects and the governmental logic associated with them.

Key-words: Education; Civil Society; State; Methodology; Research.

DOI: 10.12957/mnemosine.2020.52695

\section{Introdução}

Expor o coração de um projeto de pesquisa, a motivação que o fez nascer, o tom do seu olhar não é tarefa fácil. Quatro elementos fundamentais - um ótico, um histórico, um matemático e um geracional - foram motores do interesse acadêmico que acabou por suscitar esta pesquisa. 


\section{A ÓTICA}

Aos 7 anos de idade, um oftalmologista me disse que deveria usar óculos permanentes. Eu tentei resistir, me recusar, e ele foi categórico: “Deixa - falou com muita calma para minha mãe - ela vai acabar usando".

Usei. Pior ainda, comecei a gostar deles. Adequei-me. E a lembrança do diagnóstico que modificou meu rosto na temida forma permanente, a afronta da superioridade de quem auspicia o inevitável, foi ficando tênue.

\section{A HISTÓRIA}

O professor de História no primeiro ano do ensino secundário começou o curso situando numa longa linha do tempo as grandes épocas e eras da Humanidade. Estabeleceu a divisão entre História e Pré-história, e disse que o surgimento da escrita marcava a transição de uma para outra.

Como? A escrita? Eu não entendi. Havia povos que viviam sem escrita ainda nos nossos dias. E pessoas no nosso país que também não participavam do código escrito. O que era aquela linha do tempo? A quem representava?

\section{A MATEMÁTICA}

Foi no mesmo ano que eu aprendi a segunda coisa mais surpreendente sobre as linhas. Um descobrimento que me permitiu, aos 12 anos, entender mais política que geometria.

A professora de matemática deu uma semana para pensar na seguinte pergunta de dever de casa:

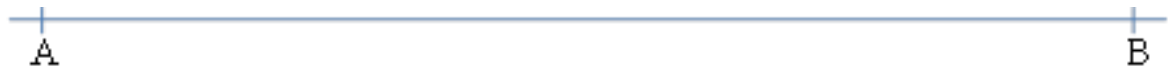

Se o ponto $\mathrm{B}$ é fixo e o ponto A se move na direção de $\mathrm{B}$, é possível que A se aproxime infinitamente de B, mas nunca chegue a alcançá-lo?

\section{AS GERAÇÕES}


Nasci num Uruguai redemocratizado. Só fui entender muito mais tarde o que isso tentava significar. Meus pais viajaram muitas vezes comigo e o meu irmão para visitar a família no Brasil. A família que a ditadura tinha separado, mas a família que sem as ditaduras não teria se conhecido.

Um ponto pode, sim, se aproximar infinitamente de outro, e não alcançá-lo jamais. É só ele se acercar sempre menos do que falta. Simples. Eduardo Galeano diz que a utopia, aquilo que não se pode nunca atingir, serve justamente para andar, para mover-se.

Ella está en el horizonte - dice Fernando Birri - Me acerco dos pasos, ella se aleja dos pasos. Camino diez pasos y el horizonte se corre diez pasos más allá. Por mucho que yo camine, nunca la alcanzaré. ¿Para qué sirve la utopía? Para eso sirve: para caminar.(GALEANO, 2001: 230)

Mas e se houvesse certa intencionalidade, uma vontade política, para um movimento sempre insuficiente?

A história dos que ficam por fora da linha do tempo da Humanidade com $\mathrm{H}$ maiúsculo se parece com a história do ponto A. Mas é também a história dos óculos. A história das esmagadoras perspectivas permanentes receitadas por alguém que tudo sabe e anula a luta antes de esta poder estabelecer-se num campo de batalha.

A geração de uruguaios nascidos depois de $1985^{1}$ tem também vivência e memória do período anterior. Somos pontos em múltiplas linhas: as da História Universal, as da geometria-política, as das estradas que nos levaram a conhecer as famílias de longe. E temos óculos. Mas estes não hão de ser necessariamente permanentes. O especialista pode errar nisso.

Questionar os olhares dominantes na História, pesquisar nos seus discursos procurando as micro-histórias e as histórias dos que sempre ficam relegados, gerar memória, eis o coração da pesquisa. A História, como um meio institucionalizado de construção de memória, é um elemento de subjetivação capaz de produzir modos de ser e pensar.

A existência de pessoas submersas na pobreza ${ }^{2}$, mesmo num contexto recente de redução significativa dos indicadores de indigência e pobreza no Uruguai, contradiz a pretensão democrática do país; as verdades instituídas em torno da democracia burguesa. 
Como se situam as autoridades e os órgãos públicos de governo e a sociedade civil perante as dificuldades de democratização da sociedade uruguaia, frente ao desafio de garantir a vida digna de todos os seus cidadãos? É relevante estudar os mecanismos que contribuíram para a geração e a continuidade dessa situação, bem como as iniciativas que tentam instaurar uma realidade alternativa. Nesse contexto, ganha particular importância a revisão crítica das estratégias político-pedagógicas desenvolvidas no país.

$\mathrm{Na}$ América Latina, e particularmente no Uruguai, tradicionalmente reconheceu-se no Estado - como entidade administrativa e legal da unidade nacional - a instituição responsável pela educação dos cidadãos, concentrada em escolas geridas pela administração pública. Mas organizações civis de diversos tipos têm participado da atividade educativa para determinados grupos da sociedade: religiosos, étnico-culturais, de classe.

$\mathrm{O}$ objeto da pesquisa ${ }^{3}$ desenvolvida e aqui apresentada diz respeito à relação, a partir da redemocratização dos anos 1980, entre as instâncias públicas governamentais e a sociedade civil organizada que intervém na educação das classes populares no Uruguai.

\section{O objeto e o objetivo da pesquisa}

O sistema público de educação instaurado no Uruguai na segunda metade do século XIX foi visto historicamente como o espaço idôneo para a produção de cidadania e a construção de uma sociedade coesa que fomentasse a mobilidade social. A educação primária pública estendeu-se no país durante a primeira metade do século $\mathrm{XX}$, ganhou prestígio e passou a ser reconhecida internacionalmente pelas elevadas taxas de matrícula.

A construção de um discurso sobre a coesão social da sociedade uruguaia e as vantagens oferecidas pelo seu sistema público de instrução restringia-se a algumas zonas dos âmbitos urbanos, principalmente à cidade de Montevidéu, e, sobretudo, aos amplos setores de classe média (MARTINIS, 2011). Mas no meio rural persistiam antigas situações de exploração e pobreza. Além disso, diante das épocas de recessão econômica e crise política que marcaram a segunda metade do século $\mathrm{XX}$, a reputação da escola como produtora de integração e como meio de ascensão social foi posta em dúvida.

Reconheceu-se uma crise da educação. Em termos gerais, as taxas de alfabetização continuaram altas e mantiveram-se os índices de universalização do ensino primário. 
Entretanto, cresceu a preocupação por repetência, "abandono" e "fracasso escolar". A abrangência e a qualidade do ensino secundário também foram motivos de apreensão.

A partir dos anos 1960, e com maior ímpeto nas décadas seguintes, surgiram iniciativas sociais e educativas da sociedade civil, cuja finalidade incluía a superação de algumas das dificuldades ou deficiências do sistema de educação pública: alfabetização de jovens e adultos, inserção e reinserção de crianças e adolescentes no sistema formal de ensino, programas de apoio escolar supletivos ou paralelos aos cursos escolares. Durante a ditadura (1973-1985), as organizações da sociedade civil representaram uma forma oportuna de organização coletiva. Muitos militantes e intelectuais da área social e de outros espaços viram nelas um canal auspicioso para o desenvolvimento das suas práticas, enquanto outras possibilidades se mantinham interditadas. A sociedade civil organizada, na forma de Organizações não Governamentais (ONGs), movimentos sociais ou religiosos, sindicatos, fundações e outras instituições, foi responsável pela criação e implementação de grande parte dos projetos que tratavam da educação de setores específicos da sociedade, particularmente das classes populares. Algumas organizações geraram formas de colaboração com os organismos governamentais, atuando dentro do sistema público de ensino ou recebendo financiamento público para programas, projetos e ações concretas. Esse processo intensificou-se após o fim da ditadura civil-militar.

A adoção do modelo neoliberal - processo que foi iniciado na época anterior ao Golpe de Estado de 1973, aguçou-se durante o período ditatorial, mas foi consolidado e aprofundado nos anos posteriores a ele, principalmente nos anos 1990 - frustrou as expectativas de mudanças substanciais na condução da política econômica, social e educativa.

Os dados aqui expostos e as análises originadas na pesquisa orientam a compreensão da sociedade civil e do governo como formas mutuamente não excludentes de execução de um projeto político que há de se colocar em análise. Ao invés da oposição entre Estado e sociedade civil, formulada no século XVIII pelos economistas liberais, a noção foucaultiana de sociedade civil como parte ativa nas relações de governamentalidade, produto e produtora de subjetividades, sustenta tal hipótese. Foucault (1985: 218) contesta essa ideia da sociedade civil como território limítrofe do Estado no qual os processos 
políticos e econômicos são autônomos, e estuda as relações e sistemas de dependências do campo político-econômico observando outras complexidades.

O Estado não é na história essa espécie de monstro frio que não parou de crescer e de se desenvolver como uma espécie de organismo ameaçador acima de uma sociedade civil. Tratar-se-ia de mostrar como uma sociedade civil, ou antes, simplesmente uma sociedade governamentalizada instituiu, a partir do século XVI, certa coisa, certa coisa ao mesmo tempo frágil e obcecante que se chama Estado. Mas o Estado nada mais é que uma peripécia do governo, e não o governo que é um instrumento do Estado. Ou, em todo caso, o Estado é uma peripécia da governamentalidade. (FOUCAULT, 2008b: 331)

Interessa neste trabalho pensar o Estado em relação a uma lógica de governo, uma governamentalidade da qual a sociedade civil faz parte. Uma precaução se faz necessária a partir desta compreensão do Estado como forma abrangente: evitar o uso, muito comum no material consultado e nas entrevistas realizadas, da terminologia "Estado e sociedade civil" ou "Estado - sociedade civil" que, ao diferenciá-los, implicitamente alude à oposição ou separação entre ambos.

A primeira alternativa ensaiada, a saber, falar de instâncias governamentais e instâncias não governamentais, também resulta escorregadia, pois este trabalho observa que o poder de governo, no sentido desenvolvido por Foucault, recai sobre ambas as instâncias, e é em ambas produzido. De fato, a palavra governo também deve ser lida com atenção para distinguir a instituição "governo" (da qual deriva a distinção governamental / não governamental) da atividade de reger a conduta dos homens, atividade que traduz uma forma de poder e que acontece mediante instrumentos estatais.

Resta a possibilidade de pensar em organismos públicos e privados, embora as áreas cinzas dessa divisão também tenham que ser postas em análise. Cabe considerar os espaços do público e do privado como instâncias não dicotômicas do campo social, e avaliar teoricamente a dicotomização do governamental e o não governamental:

[...] em termos históricos, a sociedade civil é uma relação que emerge na sociedade moderna no contexto do espaço público; é uma das manifestações das dicotomias operadas por um sistema de privatização; é uma forma de manifestação do público em um mundo privatizado. (SCHEINVAR, 2009: 43)

O objetivo principal da pesquisa foi o de identificar e analisar a racionalidade predominante na proposta político-pedagógica do Uruguai, no contexto da ação do setor público e da sociedade civil em relação à educação das classes populares em Montevidéu e sua área metropolitana, a partir da redemocratização da década de 1980. 
Especificamente, interessa colocar em análise as implicações políticas, sociais e educativas da participação da sociedade civil na educação dos estratos pobres da sociedade, e observar de que maneira ela está articulada à lógica burguesa, dominante na pedagogia uruguaia desde o século XIX, bem como à governamentalidade neoliberal, estabelecida incipientemente no país desde o período ditatorial e fortalecida na pós-ditadura.

É relevante, em termos político-pedagógicos, a delegação por parte da administração pública de certos espaços educativos à sociedade civil, particularmente quando se trata da educação dos setores pobres da sociedade e quando são pensados como paliativos de caráter meramente compensatório de uma situação de emergência social. Surge assim a hipótese do vínculo que se pode gerar entre as propostas educativas oferecidas para as populações mais pobres e os mecanismos de controle e governo da pobreza (no sentido apontado por MARTINIS, 2006a, 2006b).

\section{2. $O$ trabalho de campo}

Richard Sennett lê da seguinte maneira as entrevistas como ferramenta de pesquisa:

Nós passamos horas ouvindo as pessoas explicarem o que pensam, sozinhas ou em grupos, seus valores, medos e expectativas. À medida que passam as horas, tudo isso é revisto e reformatado ao ser reproduzido. $O$ etnógrafo atento aguça a audição para aquilo que leva as pessoas a se contradizerem ou se meterem num beco sem saída do entendimento. $O$ entrevistador não está ouvindo um relato imperfeito, e sim prestando atenção a uma investigação subjetiva da complexidade social. As ambiguidades, deformações e dificuldades que se manifestam num depoimento pessoal sobre questões como Fé, Nação e Classe constituem o entendimento que um indivíduo tem da cultura.

Esta ferramenta sociológica é ao mesmo tempo adequada e inadequada para a revelação do espírito inovador dos dias de hoje. Adequada porque a ênfase da sociedade nos fluxos e na fluidez converge com o processo de trabalhar uma interpretação na nossa mente. Inadequada porque a maioria dos entrevistados em pesquisas mais aprofundadas aceita participar para chegar a conclusões, a uma explicação de sua própria posição no mundo. A fluidez frustra este desejo [...]. (SENNETT, 2006: 19)

A ferramenta metodológica que orienta a análise realizada do material obtido, em particular as falas, as ambiguidades e as contradições, os elementos que compõem a própria pesquisa estão atravessados por apreciações subjetivas, são produzidos subjetivamente e não podem ser pensados como pontos fixos que nos guiam a uma série coerente e clara de conclusões como destino final. A fluidez de que fala Sennett é fonte de frustração, mas é também o que possibilita pensares abertos e linhas de fuga ${ }^{4}$. 
A opção feita por um pensar que não se guie pelas polarizações dicotômicas do bem e do mal, do verdadeiro e do falso, do dentro e do fora, do indivíduo e da sociedade, da sociedade e do Estado, é uma busca sem norte (nem sul). Afinal, o que é o norte senão uma convenção? Um ponto fixo e arbitrário que não se discute? Ora, nem por isso a busca é então desorientada. Há pistas e rastros. Há inúmeras direções, linhas e estradas. Há um meio imanente, ou um plano onde crescem trepadeiras. Há um texto e um leitor. "É que o começo não começa senão entre dois, intermezzo" (DELEUZE; GUATTARI, 2012, v.4: 141).

As entrevistas realizadas com representantes ${ }^{5}$ de cinco das maiores ONGs atuantes no campo educativo em Montevidéu e na área metropolitana são referências de análise das práticas educativas e dos processos vividos pela sociedade civil uruguaia em termos da sua relação com as políticas públicas. A pesquisa também tomou em consideração textos produzidos no contexto de organismos internacionais, de instituições governamentais e de organizações da sociedade civil $^{6}$ que avaliam, descrevem, analisam ou justificam as políticas executadas.

As entrevistas se organizam em quatro eixos temáticos. $\mathrm{O}$ primeiro correspondeu à origem, à história e à atualidade das organizações. Outro eixo explorou as atividades desenvolvidas e a conceituação da prática educativa das instituições. O seguinte teve a ver com o modo como se vê "o outro", o educando, e a população alvo das práticas. Finalmente, o quarto eixo tratou do vínculo das organizações com as políticas públicas.

As entrevistas não contemplaram fatores relacionados com as condições materiais ou contratuais de trabalho dos educadores e demais funcionários das organizações, nem da sua formação profissional. Estes aspectos, portanto, não fazem parte das análises que se desenvolvem no presente trabalho. Este texto coloca a ênfase nas produções de sentido dos depoimentos recolhidos, assim como nas relações dessas construções discursivas com as lógicas mais amplas da política educativa. Futuras pesquisas, voltadas para os aspectos formais e práticos do trabalho educativo realizado pelas organizações em questão, poderão complementar e dialogar com o estudo aqui desenvolvido.

Nas respostas, quando os entrevistados identificam etapas da vida institucional da ONG à qual pertencem, suas falas transitam por observações sobre o cotidiano da organização, passando por preocupações pedagógicas e considerações sobre o contexto 
político uruguaio e internacional, assim como sobre as mudanças nas modalidades de relação do público com o privado, mostrando a articulação de todas as dimensões pelas quais circulam os depoimentos.

Além de momentos particulares vividos por cada organização e identificados por elas como marcos da vida institucional, os entrevistados registram diferentes etapas segundo dois aspectos: 1) os critérios operativos e metodológicos da prática educativa da organização, 2) a organização financeira e do trabalho.

1) O primeiro reúne os seguintes enfoques:

a) O tipo e a quantidade de projetos contemplados pela organização e o crescimento da população alvo.

"Estava tudo misturado porque atendíamos juntos, mais ou menos ao mesmo tempo, adolescentes e crianças. Depois [...] separa-se escolares, funda-se Casa Joven, Centro Juvenil e depois escolares; começam a se separar." [sic] (Instituição 1, Entrevista 2, tradução nossa)

b) Os conceitos metodológicos que marcaram mudanças no desenvolvimento da instituição; por exemplo, o conceito de direitos utilizado na prática ou os objetivos perseguidos.

“[...] um primeiro recorte pelos direitos humanos em geral, um segundo recorte pelos direitos mais vinculados a todos os processos da ditadura, um terceiro recorte [...] de direitos de crianças e adolescentes, e um quarto recorte que começa a dizer 'ora não... não perder a integralidade de todos os direitos'.” [sic] (Instituição 4, Entrevista 1, tradução nossa)

"[...] na fundação desta instituição estava a ideia da reabilitação, [...] o positivismo, mais vinculado à medicina, à psiquiatria, [...] isso vai mudando e começam a tomar força colocações da ordem do social e, bom, o que marca significativamente a fins dos anos 1980 e principio dos 1990, é a Convenção dos Direitos da Criança." [sic] (Instituição 1, entrevista 1, tradução nossa)

c) Os conceitos sobre o outro.

"Posteriormente foram-se adicionando novas experiências de acordo com algumas inquietações, mas estas três coisas: crianças em situação de rua, adolescentes infratores em conflito com a Lei e egresso, se continuou." [sic] (Instituição 3, entrevista 1, tradução nossa)

2) O segundo aspecto (a organização financeira e do trabalho) engloba os seguintes critérios de periodização: 
a) Os indicadores de formalização como a obtenção de registro jurídico, a profissionalização da gestão administrativa, os profissionais contratados, a quantidade de funcionários, a adoção de um gerenciamento de tipo empresarial.

“[...] Aparece nesta etapa a pessoa jurídica, e se toma uma estratégia de ter um encrave territorial. [...] todo aquele movimento de voluntariado [muda], algumas de essas pessoas começam a ter um trabalho de caráter remunerado, mais permanente, já não são atividades pontuais, são atividades mais sistemáticas." [sic] (Instituição 5, entrevista 1, tradução nossa)

"Um grupo de jovens decidiu fazer algo pelas crianças de rua, [...] começou-se com alguns acampamentos, e depois [...] foi-se tornando um pouco mais profissionalizado, Foi incorporando educadores sustentados e finalmente [...] decidimos formar una instituição [...]. Passaram de 1973 a 1990, 17 anos, passaram 300, 400 não sei quantos garotos.” [sic] (Instituição 3, entrevista 1, tradução nossa)

“[...] o inicio atado um pouco mais à religião [...] foi tipo a etapa mais mística... [...] E a última etapa, na qual nós, os trabalhadores, temos nos posicionado como trabalhadores e fizemos que a instituição se posicionasse também como empresa." [sic] (Instituição 3, entrevista 2, tradução nossa)

b) As fontes de financiamento e recursos, e o tipo de vinculação com os organismos públicos.

“[...] um primeiro nascimento que tem a ver com o processo de cooperação internacional na década de 1960, 1970, 1980, há um processo de transição entre 1980 e 1990, de articular cooperação internacional com políticas públicas e fundos próprios e depois há um momento mais atual que tem a ver com uma porcentagem muito mais alta de políticas públicas, de financiamento institucional com políticas públicas." [sic] (Instituição 4, Entrevista 1, tradução nossa)

“[...] os convênios, e o convênio com INAU ${ }^{7}$ propriamente dito, que fomos dos primeiros convênios que INAU fez, com o âmbito privado e, bom, a partir de aí começa a subvencionar-se o tema dos salários para os educadores, que, bom, isso permitiu incorporar gente, trabalhar de outra maneira, como mais no projeto educativo, tendo recursos econômicos." [sic] (Instituição 2, entrevista 2, tradução nossa)

Os critérios de ambos os focos aparecem vinculados entre si e necessariamente influenciam uns aos outros. Particularmente, o ingresso na órbita dos programas de política pública com orçamentos de organismos governamentais é um fator capaz de mudar o rumo da vida institucional das organizações civis e tem consequências profundas nos demais aspectos: os profissionais exigidos para a execução dos programas, as populações com as quais se trabalha, a forma de administração, a conceituação da prática educativa. 


\section{Análise e reflexões}

Quais as racionalidades em jogo no texto que surge, nas palavras que se pronunciam? No caso da pesquisa, na construção do diálogo com os entrevistados, qual a racionalidade que circula por fora? Genealogicamente, pode-se ir atrás dos rastros das práticas que produzem os regimes de verdade. E, cartograficamente, pode-se tentar traçar o mapa das linhas, segmentos e fluxos que as sulcam. O intuito é de desnaturalizar as produções de discursos e práticas historicamente dominantes que, por terem sido abstraídas dos contextos históricos das suas criações, podem ser tidas como dados a priori ou como verdades instituídas.

Estudar alguns dos fenômenos apontados pelos entrevistados no trabalho de campo permite colocá-los no contexto nacional, regional e global de instauração de uma governamentalidade neoliberal, e visualizar como esses movimentos são desdobrados por formas macro de condução política, sendo, ao mesmo tempo, desdobramentos delas. Pensar a racionalidade governamental que se depreende das práticas educativas desenvolvidas por organizações da sociedade civil com crianças, adolescentes e famílias pobres de Montevidéu conduz à observação do tecido de linhas e segmentos de subjetivação que se constrói nessas práticas, e como nele se articula a estigmatização da alteridade reconhecida nos educandos com os discursos da inclusão e dos direitos universais.

A contextualização do problema exige trazer à tona o momento histórico da "modernização" do Estado uruguaio, no século XIX, e o processo de instauração do sistema de educação pública à luz das relações de poder que se consolidavam no país, principalmente a respeito da organização do trabalho e da reprodução da mão de obra. De igual modo, a introdução de princípios da política neoliberal no mundo ocidental da segunda metade do século XX e suas consequências no Uruguai e na América Latina, considerando hipóteses teóricas já consagradas referentes à dependência dos países periféricos, leva também à revisão do processo de adoção de políticas neoliberais e serve como marco para a reflexão sobre as implicações que o Capitalismo Mundial Integrado ${ }^{8}$ sob a lógica neoliberal - teve nas políticas de educação no Uruguai. Interessa particularmente destacar os mecanismos de cooperação internacional que tecem redes de ajuda em que intervêm governos, organizações da sociedade civil e organismos multilaterais, cujos agenciamentos são subordinados a condições políticas. Por último, em 
termos de contextualização, deve considerar-se a normativa uruguaia quanto às formas de articulação dos órgãos públicos com a sociedade civil e problematizar os caminhos de adaptação e de resistência que as organizações percorrem quando entram no terreno da política pública.

A sociedade civil explicita a arena das disputas, dos tensionamentos. Encontram-se nela múltiplas resistências. Verificam-se, em diversos momentos da história uruguaia, articulações da sociedade civil com a política pública governamental, principalmente em três instâncias: por uma parte, a sociedade civil é ativa na definição da agenda dos campos políticos em que atua, colocando iniciativas para serem recolhidas pelos poderes públicos ${ }^{9}$; ela também atua resistindo, corrigindo e exigindo modificações em políticas públicas ensaiadas pelos organismos governamentais ${ }^{10}$; por último, ela pode participar da política pública fazendo parte da formulação dos programas ou se encarregando da sua implementação. Os exemplos recolhidos ao longo deste trabalho dizem respeito a esta última modalidade de articulação entre a sociedade civil organizada e a administração pública.

Embora no conjunto das organizações que atuam na área educativa em Montevidéu e na zona metropolitana encontrem-se instituições com variadas modalidades de ação e com diferentes fundamentos políticos, filosóficos e educativos, a grande tendência nesse conjunto é de organizações que nasceram com posturas críticas frente a algumas características do sistema formal de ensino e das políticas sociais do Estado. O contexto social do período ditatorial uruguaio propiciou a criação de organizações da sociedade civil que pretendiam operar por práticas alternativas, da ordem do democrático e em defesa dos direitos vulnerabilizados ou anulados pela ditadura. O processo de institucionalização dessas organizações e a sua relação com movimentos internacionais de escala global, bem como com os organismos públicos, articula movimentos molares e moleculares no vaivém da captura e da fuga entre a máquina de guerra e o aparelho de Estado.

No fim dos anos 1980 e durante os 1990, as organizações civis viram-se condicionadas pela necessidade financeira de substituir os recursos aos quais, até então, acediam por meio da cooperação internacional e tinham começado a diminuir. A conjuntura política gestada no país, que se orientava pelos preceitos neoliberais favoráveis à privatização, e a situação financeira das organizações coincidiram para promover a sua 
vinculação com organismos governamentais, que começaram a contratá-las para a implementação de projetos e programas. A atuação direta na efetivação prática das políticas educativas e sociais exigiu adaptações para cumprir os requisitos dos contratos e provocou mudanças na vida institucional das organizações, no seu formato administrativo e formal, nos seus quadros de trabalho, nas populações atendidas, nas suas ofertas educativas.

A modalidade de gestão e execução de políticas sociais e educativas através da sociedade civil organizada está em vigor e em expansão, no Uruguai, desde os anos 1990, razão pela qual se pode afirmar que é uma política de Estado. Suas origens se vinculam com o neoliberalismo e superam amplamente o contexto nacional. Diretrizes dos organismos multilaterais e consensos internacionais registrados em grandes convenções mundiais apontam as vantagens práticas desta política de terceirização em termos de “capital humano", "eficiência", "resultados", "competitividade”, "progresso técnico", “competências e destrezas", conforme problematizado ao longo desta pesquisa.

La educación es el instrumento privilegiado para elevar la competitividad sistémica de las economías, una competitividad no centrada en bajos salarios o explotación excesiva de los recursos naturales, sino en la incorporación de progreso técnico. La competitividad sistémica requiere, a su vez, de un incremento sistémico de la calidad de los recursos humanos y de la adquisición de nuevas destrezas. [...] La principal limitación de la región ha sido, en este sentido, la restringida disponibilidad de jóvenes que cuenten con una educación y capacitación adecuadas al incorporarse a la población económicamente activa. Este factor es especialmente crítico cuando consideramos las bajas tasas de egreso al final de la educación secundaria en casi todos los países de la región. Por otra parte, es necesario mejorar la calidad y la pertinencia de la educación tanto secundaria como terciaria, adecuando la oferta a las características de los sistemas productivos y del mercado laboral de cada país. (CEPAL, 2000: 111)

Vale lembrar que Foucault (2008a) identificou como um dos grandes interesses dessa Teoria do Capital Humano a possibilidade de pensar como pertencente ao âmbito econômico certo campo que pertencia, até então, a uma esfera não-econômica (FOUCAULT, 2008a: 302). Desse modo, formar capital humano é formar "essas espécies de competência-máquina" (FOUCAULT, 2008a: 315). A Teoria do Capital humano pensa o humano como aquilo que é capaz de produzir renda ou ser remunerado por isto. Formar capital humano é, então, finalmente, "fazer o que se chama de investimentos educacionais" (FOUCAULT, 2008a: 315).

A gestão de políticas públicas por parte de organizações não governamentais agita e controverte a articulação entre o particular e o comunal, o público e o privado, o individual 
e o coletivo, "que não é outra senão a tensão entre liberdade e igualdade" (SCHEINVAR, 2009:43).

É relevante que o campo educativo fosse o privilegiado para os ensaios da interação dos órgãos de governo com a sociedade civil organizada, uma vez que a "educabilidade" das crianças e dos jovens pobres foi posta em dúvida, quando não negada, em discursos ora vitimizantes ora culpabilizadores, como os produzidos no contexto dos anos 1990, que os definiram segundo uma série de adjetivações despotencializadoras.

A concepção economicista da educação, a fragmentação da oferta educativa e a precarização dos sistemas educativos, principalmente dos setores relacionados com as camadas pobres da população, combinam-se para reafirmar e legitimar a ordem estabelecida. A "expansão condicionada" dos sistemas de educação, analisada por Gentili (2009), é um fenômeno comum a todos os países da região e denota o caráter antidemocrático das sociedades latino-americanas: "os poderosos parecem ter aceitado que as massas deveriam ter direito à educação, desde que o sistema educacional se enfraquecesse como a instituição em cuja permanência esse direito se garante" (GENTILI, 2009:1071).

No período estudado, as políticas abraçadas no plano econômico e político no Uruguai, como em outros países do continente, e as dificuldades desses Estados para assumir posturas transformadoras resultam relevantes para entender o conservadorismo das políticas educativas, cujos modelos de reforma se propuseram para melhor se adaptar aos cânones capitalistas da economia mundial.

A lógica cultural neoliberal impõe certas "verdades", domina as novas tecnologias, cria uma superficialidade consumista; em suma, é eficiente na criação de uma subjetividade funcional ao mercado. Elementos das formulações higienistas presentes nos documentos e discursos oficiais permeiam também os depoimentos dos entrevistados. Esta constatação diz respeito à naturalização de uma lógica estriada e disciplinadora da educação. A produção de subjetividade capitalista naturaliza as práticas de intervenção nas famílias das classes populares que buscam enquadrar as suas vidas de acordo com os parâmetros dominantes, cujo caráter histórico e datado é também naturalizado e foge, portanto, à problematização. 
No contexto de crises econômicas e políticas, com a acentuação da pobreza e da miséria instaladas principalmente nas faixas etárias infantis e juvenis, o percurso vivenciado pela educação uruguaia exibe os resultados das prioridades neoliberais. A hipótese elaborada por Antonio Romano (2009), de um golpe na educação no Uruguai préditatorial, é de grande importância. Ela dá visibilidade ao enrijecimento coercitivo que o modelo precisou assumir para garantir a continuidade de uma linha hegemônica que provém da época colonial. Quando o contexto regional e mundial propiciou questionamentos ao modelo político-econômico hegemônico, a educação virou foco de atenção para políticas repressoras e antidemocráticas, como as vivenciadas no período ditatorial.

Outra cara da mesma lógica é a que sobrecarregou os centros educativos de determinadas zonas de Montevidéu, e do país em geral, com responsabilidades sociais, sobrepondo-as à tarefa puramente educativa, quando o cenário educativo da pós-ditadura, com altas taxas de repetência e evasão, evidenciava o fracasso da pretensão igualitária e democrática da escola gratuita, laica e obrigatória.

Longe de atribuir o fracasso à lógica pauperizadora essencial aos interesses de perpetuação do status quo das relações de poder, produziram-se discursos culpabilizantes. De um lado, os próprios alunos e as suas famílias eram responsáveis por malograr o processo educativo, não possuindo condições necessárias de educabilidade e merecendo, portanto, um tratamento diferente que "fizesse o possível” para eles, alunos, vencerem essa defasagem. De outro lado, o contexto de pobreza e violência era a causa da instabilidade escolar, dificultando a tarefa educativa e fazendo com que a atenção devesse ser centralizada no premente cuidado das necessidades básicas dos alunos.

Assim, ao mesmo tempo que o ensino formal se fragmenta e se torna precário, aumenta a proliferação de ofertas de cursos supletivos, de apoio para o contra-turno escolar, de ensino profissionalizante, e outras modalidades, das quais, em sua ampla maioria, se encarregam organizações da sociedade civil, e nas quais é também ostensível a intervenção nos hábitos e nas formas de vida das crianças, dos jovens e das famílias pobres.

O que caracteriza as estratégias e os procedimentos práticos da política social e educativa decorrentes de uma racionalidade como a descrita acima é o governo da pobreza. É nessa instrumentalização prática da política que a sociedade civil intervém. As suas lutas, 
as suas resistências e as suas renúncias se inscrevem nesta esfera política e são, por isso, de grande relevância no panorama educativo nacional.

Para Foucault (1995), o Estado nas sociedades contemporâneas não pode ser lido como o único palco para o exercício do poder. As relações de poder não derivam do Estado como entidade única. Porém o trabalho do autor estabelece que as relações de poder sofreram, de diferentes maneiras, no âmbito familiar, jurídico, econômico, pedagógico, médico, uma contínua estatização. Elas foram governamentalizadas e garantidas pelo seu ingresso na órbita das instituições do Estado.

No texto "O sujeito e o Poder", Foucault (1995) sugere cinco pontos a serem levados em consideração no estudo das relações de poder. A saber: 1) o sistema de diferenciações, 2) o tipo de objetivos, 3) as modalidades instrumentais, 4) as formas de institucionalização, 5) os graus de racionalização. Estes pontos se entrecruzam e todos eles implicam em considerações micropolíticas e macropolíticas.

O trabalho de Foucault serve, mais uma vez, para situar algumas das reflexões desenvolvidas nesta pesquisa. As descrições da alteridade, alvo das políticas elaboradas para os setores pobres da sociedade uruguaia, como carente, problemática e patologizada, produzem a diferenciação entre dois mundos que remetem a uma fragmentação social. Em palavras de Foucault (1995: 246): “toda relação de poder opera diferenciações que são para ela, ao mesmo tempo, condições e efeitos". O objetivo principal que surge desta diferenciação é o de incluir. Incluir os jovens no mundo do trabalho e as crianças no sistema de ensino formal, como meio para alcançar a "inclusão social”. Desta forma, só cabem questionamentos para o mundo dos "excluídos", dos subalternos, enquanto o mundo dos "incluídos" é naturalizado como o bom e o desejável. As raízes da racionalidade política que produz como efeito visível essa fragmentação social não são postas em questão. Decorrem deste panorama modalidades instrumentais de caráter biopolítico, de segurança e de controle voltadas para as famílias das classes populares. Todas as dobras da subjetivação são abarcadas. As formas institucionais, por sua parte, como tecnologia de governo do aparelho de Estado, pertencem ao espaço de racionalidade sedentária e hierarquizada, na qual prima uma lógica arborescente que conduz ao decalque, à reprodução. 
O processo que deu maior ingerência às organizações civis na execução da política pública não é uma singularidade uruguaia. Graciela Cardarelli e Mónica Rosenfeld (2000) estudam o caso argentino, no qual se pode observar uma reestruturação políticoadministrativa, institucional e programática similar à vivenciada no Uruguai, que abandona o "universalismo" e privilegia políticas focalizadas e compensatórias. Este esquema implica o que as autoras chamam de welfare mix: o favorecimento de formas associativas entre o setor do governo "dedicado aos pobres" e as organizações da sociedade civil, de forma que o Estado "assistencial", que alocava recursos nos organismos públicos, passa a financiar atores da sociedade civil. Além de um aumento de demanda financeira por parte do setor privado, os perigos observados neste mix assistencial incluem novas formas de assistencialismo, clientelismo e tecnocracia (CARDARELLI; ROSENFELD, 2000: 28). Resta aguçar o olhar ainda mais para começar a enxergar e imaginar as formas em que saberes específicos e experiências do cotidiano possam se articular em práticas alternativas, potencializar processos singulares e afastar-se do exercício de poder dirigido à gestão e ao controle.

\section{Considerações finais}

Donzelot (2001) entende que há uma tríade - constituída do judiciário, do psiquiátrico e do educacional - que compõe o trabalho social. Esta pesquisa, pelo tipo de instituição com a qual lidou, pelo foco temático das entrevistas realizadas e pela análise que delas foi feita, centrou-se principalmente no aspecto educacional. Além disso, o universo pesquisado só incluiu um dos grupos de atores envolvidos nas práticas educativas: as organizações da sociedade civil.

Na atualidade política do Uruguai, assim como de outros países da região, verificase a interrupção de um processo de transformação pautado pela busca da compatibilidade entre o projeto político da "esquerda" e o sistema capitalista liberal. Neste complexo cenário político, o debate e a análise das articulações entre o público e o privado, o governamental e o não governamental, requerem ir além das considerações sobre as demandas específicas e instrumentais de um e outro extremo do continuum, para refletir sobre o sentido social, político e ético das suas práticas e discursos. 
"Uma revolução - diz Rancière (2009) - é uma ruptura na ordem do que é visível, pensável, realizável, o universo do possível”. Ressignificar a educação em relação às suas dimensões políticas, conceber uma educação comprometida com a vida como forma de resistência, requer pensá-la à luz dessa trama de possibilidades abertas. "Ampliar o pensável” propôs Graciela Frigerio (2013), e com isso deixou um convite para "associar ideias disparatadas" e "colocar perguntas descriteriosas, não só as criteriosas", para, em suma, "fazer do que há outra coisa".

Não se trata mais de impor uma forma a uma matéria, mas de elaborar um material cada vez mais rico, cada vez mais consistente, apto a partir daí a captar forças cada vez mais intensas. $O$ que torna o material cada vez mais rico é aquilo que faz com que heterogêneos mantenham-se juntos sem deixar de ser heterogêneos. (DELEUZE, GUATTARI, 2012, v.4: 141)

Surge a necessidade de pensar algo de coletivo, algo de comunitário. Um diálogo, um encontro. Estar juntos, não no sentido do consenso, uma reprodução de múltiplos decalques que poderia ser a ausência de conflito, mas como uma forma de re-territorializar algo do público.

Procurar fendas que permitam achar linhas de fuga, mesmo que encobertas, é uma opção política; reconectar os decalques no mapa do qual eles provêm, vincular as raízes e os galhos a um rizoma em construção, fazendo com que as formas naturalizadas se transmutem dando vida a outros encontros, outras figuras, outras possibilidades... Explorar os intermezzos.

\section{Referências}

CARDARELLI, Graciela; ROSENFELD, Mónica. Con las mejores intenciones. Acerca de la relación entre el Estado pedagógico y los agentes sociales. Em: DUSCHATZKY, Silvia (comp.). Tutelados y asistidos: Programas sociales, políticas públicas y subjetividad. Buenos Aires: Paidós, 2000.: 23-67

CEPAL. Equidad, desarrollo y ciudadanía. Comisión Económica para América Latina y el Caribe. 2000.

Disponível em: https://repositorio.cepal.org/bitstream/handle/11362/2686/S2006536_es.pdf;jsession $\mathrm{id}=\mathrm{F} 4627161 \mathrm{~B} 84781826$ AF0C47503EF5C6D?sequence $=2>$ Acesso em: 02 out. 2018

DELEUZE, Gilles; GUATTARI, Félix. Mil Platôs: Capitalismo e esquizofrenia $2.2^{\circ}$ ed. v.1-5. São Paulo: Editora 34, 2012. 
DONZELOT, Jacques. A polícia das famílias. $3^{\circ}$ ed. Tradução de M. T. da Costa Alburquerque; Revisão técnica J. A. Guilhon Alburquerque. Rio de Janeiro: Edições Graal, 2001.

FOUCAULT, Michel. Seguridad social: un sistema finito frente a una demanda infinita. Em: FOUCAULT, Michel. Saber y Verdad. Tradução: Julia Varela e Fernando Álvarez-Uría. Madrid: La Piqueta, 1985.: 209-228.

O sujeito e o poder. Em: DREYFUS, Hubert; RABINOW, Paul. Michel Foucault, uma trajetória filosófica (para além do estruturalismo e da hermenêutica). Tradução: Vera Portocarrero. Rio de Janeiro: Forense Universitária, 1995.: 231-249

Nascimento da biopolítica: curso dado no Collège de France (1978-1979). Tradução: Eduardo Brandão; revisão da tradução Claudia Berliner. São Paulo: Martins Fontes, 2008a.

Segurança, território, população. Curso dado no Collège de France (19771978). tradução: Eduardo Brandão; revisão da tradução: Claudia Berliner. São Paulo: Martins Fontes, 2008b.

FRIGERIO, Graciela. El trabajo de los conceptos para ampliar lo pensable. Diálogo entre disciplinas. [conferência] Em: Primer Encuentro Internacional: Educación y Psicología en el $S$ XXI. Facultad de Psicología, Universidad de la República, Montevideo, mayo, 2013.

GALEANO, Eduardo. Ventana sobre la utopía. Em: GALEANO, Eduardo. Las palabras andantes. $5^{\circ}$ ed. Buenos Aires: Catálogos, 2001.: 230

GENTILI, Pablo. O direito à educação e as dinâmicas de exclusão na América Latina. Em: Educ. Soc., Campinas, vol. 30, n. 109: 1059-1079, set./dez. 2009. Disponível em: <http://www.scielo.br/pdf/es/v30n109/v30n109a07.pdf> Acesso em: 13 nov. 2012

GUATTARI, Félix; ROLNIK, Suely. Micropolítica: Cartografias do desejo. $11^{\circ}$ ed. Petrópolis: Vozes, 2011.

INE. Evolución de la pobreza por el método de ingreso: Uruguay, 1986 -2001. Montevideo: Instituto Nacional de Estadística. 2002. Disponível em: <http://www.ine.gub.uy/biblioteca/ pobreza/Evoluci\%F3n\%20de\%201a\%20pobreza\%20en\%20el\%20Uruguay.pdf> Acesso em: 23 fev. 2014

. Estimación de la pobreza por el Método de Ingreso 2017. Montevideo: Instituto Nacional de Estadística - División Estadísticas Sociodemográficas. 2018. Disponível em:

http://www.ine.gub.uy/documents/10181/364159/Estimaci\%C3\%B3n+de+la+pobre $\mathrm{za}+$ por+el+M\%C3\%A9todo+del+Ingreso+2017/f990baaf-1c32-44c5-beda59a20dd8325c > Acesso em: 01 out. 2018

MARTINIS, Pablo. Educación, pobreza e igualdad: del "niño carente" al "sujeto de la educación". Em: MARTINIS, Pablo; REDONDO, Patricia (comps.) Igualdad y educación: escrituras entre (dos) orillas. Buenos Aires: Del Estante. 2006a.: 13-32 
Sobre escuelas y salidas: la educación como posibilidad, más allá del contexto. Em: MARTINIS, Pablo (comp.) Pensar la escuela más allá del contexto. Montevideo: Psico Libros. 2006b.: 259-270

Los procesos educativos y la cohesión social en Uruguay. Em: Seminario Cohesión social en Uruguay: balance y perspectivas. Auspiciado por CLAEH, SEGIB, OPP e AECID. 22 e 23 de março de 2011, Hotel Balmoral, Montevidéu, Uruguai.

OPP-MIDES. Reporte social 2013. Principales características del Uruguay social. Montevideo. 2013. Disponível em: <http://dinem.mides.gub.uy/innovaportal/file/61621/1/reporte-social-2013.pdf > Acesso em: 19 dez. 2019

RANCIÈRE, Jacques. Partilha do sensível. A associação entre arte e política segundo o filósofo Jacques Rancière. Entrevista concedida a Gabriela Longman e Diego Viana. Revista CULT, ano 12, n $^{\circ}$ 139, São Paulo, setembro 2009. Disponível em: < https://revistacult.uol.com.br/home/entrevista-jacques-ranciere/> Acesso em: 19 dez. 2019

ROMANO, Antonio. Transformaciones del discurso pedagógico en el Uruguay de la segunda mitad del siglo XX. Em: Jornadas de investigación en Humanidades. Montevideo: $2009 . \quad$ FHCE. Disponível em: <http://www.fhuce.edu.uy/jornadas/IIJornadasInvestigacion/PONENCIAS/ROMA NO.PDF>. Acesso em: 9 nov. 2012.

SCHEINVAR, Estela. O feitiço da política pública: escola, sociedade civil e direitos da criança e do adolescente. Rio de Janeiro: Lamparina, FAPERJ, 2009.

SENNETT, Richard. A cultura do novo capitalismo. Tradução de Clóvis Marques. Rio de Janeiro: Record, 2006.

URUGUAY. Ley $\mathrm{N}^{\circ}$ 15.501. Unidades Cooperativas de Vivienda, de 21 de diciembre de 1983. Disponível em: https://legislativo.parlamento.gub.uy/temporales/leytemp1684181.htm> Acesso em: 26 dez. 2019

Gabriela Rodríguez Bissio Facultad de Humanidades y Ciencias de la Educación (Universidad de la República)

URUGUAY E-mail:gabriela.rodbis@gmail.com

\footnotetext{
${ }^{1}$ Ano em que culminou a ditadura civil-militar que começara em 1973 no Uruguai.

${ }^{2}$ Segundo dados oficiais referentes ao ano 2017, em Monteviéu 11,1\% da população se encontra abaixo da linha de pobreza e a média nacional é de 7,9\% (INE, 2018). A pobreza no Uruguai continua a afetar em maior medida as crianças e aos jovens do que as pessoas de outras faixas etárias. Em Montevidéu, em 2017, 25,1\% das crianças menores de 6 anos se encontram abaixo da linha de pobreza (INE, 2018, p.34). Em termos gerais, a pobreza vem sendo reduzida desde 2004, quando alcançava 39,9\% da população do país (OPP-MIDES, 2013, p.41). Os anos 1980 e 1990 tiveram grave incidência da pobreza. Em 1986, um ano depois do fim da
} 
ditadura civil-militar, 46,2\% da população uruguaia vivia abaixo da linha de pobreza (INE, 2002, p.24). (Dados tomados de estudos com o critério dos ingressos como método para a definição da linha de pobreza).

3 Este estudo se originou dentro do Projeto de pesquisa El desarrollo de la educación extraescolar en Uruguay (1985 - 2007). Continuidades y rupturas en las relaciones entre educación y pobreza realizada, sob a coordenação do Professor Pablo Martinis e da Professora Eloísa Bordoli, na Faculdade de Humanidades e Ciências da Educação da Universidade da República - UdelaR, em Montevidéu, a respeito do desenvolvimento da educação extraescolar no Uruguai no período 1985-2007, no contexto das relações entre educação e pobreza. O trabalho de análise que deu lugar a este texto foi elaborado no contexto do Mestrado do Programa de Pós-graduação em Políticas Públicas e Formação Humana da Universidade do Estado do Rio de Janeiro.

${ }^{4}$ As linhas de fuga (DELEUZE; GUATTARI, 2012) se relacionam com a desterritorialização, uma vez que são as linhas de fuga as que permitem achar fendas num território e fazer com que os territórios estejam sempre em variação. Traçar uma linha de fuga é uma forma de evadir a normalização e o controle, ou melhor, criar um outro modo de ser, estar ou pensar. A fuga, fuite em francês, refere-se não só ao ato de fugir ou evadir-se, mas também ao de fluir, escoar e sumir na distância, como a fuga em profundidade num desenho. A fuga não é só uma oposição ao status quo, mas uma forma de libertação, que acha fissuras nos sistemas duros e de controle e permite criar outros horizontes pelas transversais.

${ }^{5}$ Os depoimentos recolhidos para este trabalho dissertativo dão conta da experiência de um só grupo dos atores envolvidos nas práticas educativas estudadas. Todas as falas aqui citadas foram traduzidas pela autora do original em espanhol.

${ }^{6}$ Em particular de federações e associações de OSC, tais como a Asociación Nacional de Organizaciones no Gubernamentales Orientadas al Desarrollo - ANONG Uruguay.

${ }^{7}$ Instituto da Criança e do Adolescente do Uruguai (Instituto del Niño y Adolescente del Uruguay), organismo reitor das políticas de infância e adolescência no Uruguai.

${ }^{8}$ CMI é o termo proposto nos anos 1960 por Félix Guattari como alternativa à Globalização, com o intuito de explicitar o caráter principalmente econômico da mundialização (Guattari; Rolnik, 2011: 411).

${ }^{9}$ Um exemplo dos primeiros anos do século XX é o dos sindicatos e organizações de trabalhadores que alimentaram a agenda política desse período, cujas conquistas foram de grande importância na história do país quanto ao avanço nas leis e nos direitos trabalhistas. Um século mais tarde, desde os primeiros anos do século XXI, temas como o matrimônio igualitário, a legalização da canabis e a despenalização do aborto chegaram ao Congresso após terem sido postos em pauta pelas demandas de diversos movimentos sociais.

${ }^{10}$ Por exemplo, o movimento de cooperativas de moradia organizou a oposição à Lei 15.501 (URUGUAY, 1983) de 21 de dezembro de 1983, ainda no período ditatorial. A lei estabelecia que todos os conjuntos regidos pelo cooperativismo de moradia passariam ao regime de propriedade individual e exclusiva das unidades. O movimento conseguiu viabilizar um plebiscito pela derrogação da lei em 1984. O fim da ditadura fez com que o plebiscito não fosse necessário.

${ }^{11}$ As autoras definem um setor do governo dedicado às políticas "para pobres". Este setor, que se diferencia dos âmbitos clássicos da política social para o total da população, é residual e gera políticas brandas e assistenciais (CARDARELLI; ROSENFELD, 2000: 28). 